\title{
Lipoproteins in Children Treated with Continuous Peritoneal Dialysis ${ }^{1}$
}

\author{
UWE QUERFELD, RENEE C. LEBOEUF, ISIDRO B. SALUSKY, PAULINE NELSON, \\ STEWART LAIDLAW, AND RICHARD N. FINE \\ Department of Pediatrics, UCLA School of Medicine, Los Angeles, California 90024 [U.Q., I.B.S., P.N., R.N.F.]; \\ Department of Medicine, University of Seattle, Washington 98195 [R.C.L.]; and Department of Medicine, \\ Harbor UCLA Medical Center, Los Angeles, California 90509 [S.L.]
}

\begin{abstract}
Total lipids, lipoprotein-lipids, and apolipoproteins were studied in plasma of 20 patients, aged 13.9 $\pm 3.4 \mathrm{y}$ (mean $\pm \mathrm{SD}$; range 7.4 to $19 \mathrm{y}$ ), who were treated with continuous peritoneal dialysis for a period of $2.1 \pm$ 1.2 (range 0.5 to 4.9 ) $y$. Measurements included total plasma cholesterol and triglycerides, triglycerides in the very low density fraction, and cholesterol in the very low density, low density, and high density fractions, as well as apo $A-I$ and apo $B$. The results were compared with values in 17 healthy control subjects, aged $13.0 \pm 5.1$ (range 5.1 to 19) $y$. The patients had significantly elevated levels of total plasma triglycerides, triglycerides in the very low density fraction, total plasma cholesterol, cholesterol in the very low density fraction, and cholesterol in the low density fraction, whereas levels of cholesterol in the high density fraction were normal. Plasma apo $B$ levels were elevated, but apo A-I levels were not different from controls. In addition, the nutritional status of the patients was assessed and apo A-I and apo B concentrations were measured in the dialysate of $\mathbf{1 0}$ patients. The losses of apo A-I and apo $B$ in dialysate averaged $13.4 \pm 7.4$ and $2.1 \pm 3.1$ $\mathrm{mg} / \mathrm{kg} / \mathrm{d}$, respectively. Lipoprotein profiles were not correlated with nutritional status. We conclude that pediatric patients treated with continuous peritoneal dialysis have atherogenic lipoprotein profiles, cholesterol ratios, and apolipoprotein ratios, but normal cholesterol in the high density fraction and apo A-I levels despite considerable apo A-I losses in the dialysate. (Pediatr Res 29: 155-159, 1991)
\end{abstract}

\section{Abbreviations}

C, total plasma cholesterol

CAPD, continuous ambulatory peritoneal dialysis

CCPD, continuous cycling peritoneal dialysis

HDL-C, cholesterol in the HDL fraction

LDL-C, cholesterol in the LDL fraction

TG, total plasma triglycerides

Received August 10, 1989; accepted August 20, 1990.

Correspondence and reprint requests: Uwe Querfeld, M.D., University Children's Hospital, Department of Pediatric Nephrology, Im Neuenheimer Feld 150 , D-6900 Heidelberg, F.R.G.

Supported in part by USPHS Grants RO1 DK 34523 and HL 28481, by the Peter Boxenbaum Research Fund, and Merit Review 001 of the Veterans Administration (R.C.L.). U.Q. was sponsored by a grant from the Deutsche Forschungsgemeinschaft and this work was completed during his tenure of Advanced Research Fellowship (867 F1-1) of the American Heart Association-Greater Los Angeles Affiliate. R.C.L. is a Senior Fellow of the American Heart Association-Greater Los Angeles Affiliate (816 F1).

' Presented in part at the 7th International Congress of Pediatric Nephrology, Tokyo, 1986, and at the 20th annual meeting of the American Society of Nephrology, Washington, DC, 1987.
VLDL-C, cholesterol in the VLDL fraction

VLDL-TG, triglycerides in the VLDL fraction

Hyperlipoproteinemia is present in the majority of adult (1) and pediatric (2) patients with end stage renal disease. This metabolic disturbance is of particular significance because several epidemiologic studies have shown a correlation between plasma lipoprotein concentrations and the occurrence of atherosclerosis in the general population. In these studies, HDL, as well as the main protein in this fraction, apo A-I, were associated with a protective effect against atherosclerosis, whereas high levels of LDL and apo B were found to increase the risk for atherosclerosis (3).

CAPD and CCPD are now widely accepted treatment modalities for children with end stage renal disease. It has been demonstrated that total serum lipid levels in these patients are elevated at the initiation of dialysis treatment (4) and are not significantly influenced by treatment with CAPD/CCPD over a 24-mo period (5). However, lipid levels in the different lipoprotein fractions and plasma apolipoprotein levels in children treated with CAPD/CCPD have not been well defined. Moreover, it is unknown whether continuous losses of apolipoproteins in the dialysate (6) could significantly affect plasma (apo)lipoprotein levels in these patients. Because peritoneal mass transfer is size-dependent, losses of apo A-I (apparent mol wt $28000 \mathrm{D}$ ) are likely to exceed the losses of apo B by far (apparent mol wt $550000 \mathrm{D}$ ). It is thus possible that the already disturbed lipoprotein profile of uremic patients could be further aggravated by peritoneal dialysis. This would constitute a serious disadvantage of treatment with CAPD/CCPD, considering the physiologic importance of HDL (3). Furthermore, it has not been evaluated whether lipoprotein profiles are influenced by nutritional status and/or obesity in children treated with CAPD/CCPD. Indices of obesity are correlated with serum lipid levels in normal children and adolescents (7) and obesity has been reported as an independent risk factor for atherosclerosis (8).

Our study was undertaken to evaluate whether the plasma lipoprotein profiles of pediatric patients treated with CAPD/ CCPD indicate an increased risk for the development of atherosclerosis, compared to an age-matched normal population. In addition, the impact of peritoneal dialysis on plasma apolipoprotein levels was estimated by quantification of the daily losses of apo A-I and apo B in the dialysate. Finally, anthropometric measurements were performed to detect possible correlations of the lipoprotein profiles with the nutritional status of these patients. 


\section{MATERIALS AND METHODS}

Twenty patients were studied, 10 male and 10 female, aged $13.9 \pm 3.4$ (range 7.4 to 19 ) $y$, who were treated with CAPD/ CCPD for a period of $2.1 \pm 1.2(0.5$ to 4.9$) \mathrm{y}$. All were nonnephrotic, free of peritonitis for at least $4 \mathrm{wk}$ before the study, and not receiving any drugs (including antihypertensive and immunosuppressive medication) affecting lipid metabolism. End stage renal disease was due to the following diseases: Alport syndrome $(n=4)$, renal dysplasia $(n=6)$, focal segmental glomerulosclerosis $(n=4)$, membrano-proliferative glomerulonephritis $(n=$ $1)$, rapid progressive glomerulonephritis $(n=2)$, polycystic kidney disease $(n=2)$, and Wilms tumor $(n=1)$. The control group consisted of 17 pediatric patients, 10 male and seven female, aged $13.0 \pm 5.1$ (range 5.1 to 19) y, who were hospitalized for minor surgical procedures and were free of chronic illness.

Hyperlipidemia was defined as a plasma lipid level above the 95th percentile for $\mathrm{TG}(112 \mathrm{mg} / \mathrm{dL})$ or $\mathrm{C}(197 \mathrm{mg} / \mathrm{dL})$ levels in control subjects. In addition, lipid levels of each patient were compared with the 95 th percentile or 5 th percentile of lipid levels in normal children matched for age and sex, as published by the Lipid Research Clinics (9). Among patients and controls, no differences were found between male and female participants in this study, so data were pooled for analysis.

A dietician measured the patient's height and weight, as previously described (10). The ideal body weight was calculated as the weight corresponding to the 50th percentile for height age of normal children (11). Nutritional status was assessed by calculation of the percentage of ideal body weight and percentages of "ideal" mid-arm circumference, mid-arm muscle circumference, and triceps skinfold thickness, which were defined as the 50th percentile of values in normal children (12) of the patient's height age.

The study protocol was approved by the institutional human subject protection committee and informed consent was obtained from all patients and control subjects and/or their parents before study.

Lipid determination. After an overnight fast of at least $10 \mathrm{~h}$, blood was drawn into Na-EDTA tubes and immediately analyzed for total plasma lipids and lipoprotein lipids. TG and $\mathrm{C}$ and lipid levels in lipoprotein fractions were determined by enzymatic methods using a centrifugal autoanalyzer. VLDL were isolated by ultracentrifugation at a density $<1.006 \mathrm{~g} / \mathrm{mL}$ (13). HDL were obtained from the density $>1.006 \mathrm{~g} / \mathrm{mL}$ fraction after precipitation of LDL with phosphotungstate $/ \mathrm{Mg}^{++}$(14). LDL-C was calculated as the difference between $\mathrm{C}$ and the sum of VLDL-C and HDL-C values.

Apolipoprotein quantitation in plasma. Aliquots of $1 \mathrm{~mL}$ plasma were stored at $4^{\circ} \mathrm{C}$ and concentrations of apo A-I and apo B were measured within $2 \mathrm{wk}$. The levels of plasma apo A-I and apo $B$ were determined by radial immunodiffusion (15) using commercially available kits (Tago, Burlingame, CA and Boehringer, Mannheim, FRG, respectively). The interassay variation was 10 and $12 \%$, respectively, for the apo A-I and apo B assays; intraassay variation was $5 \%$ with both methods.

Apolipoprotein quantitation in dialysate. The dialysate effluent from 10 patients, aged $15.6 \pm 4.0$ (range 10 to 20.7 ) y, was collected in sterile bags for analysis of total protein and apolipoprotein content. The total 24 -h dialysate outflow volume was measured and aliquots were stored at $4{ }^{\circ} \mathrm{C}$ with the addition of $0.02 \%$ (final concentration) $\mathrm{NaN}_{3}, 0.04 \% \mathrm{NaEDTA}$, and $0.005 \%$ gentamicin and analyzed within $2 \mathrm{wk}$. An aliquot $(50 \mathrm{~mL})$ was adjusted to a solution density of $1.21 \mathrm{~g} / \mathrm{mL}$ by dialysis against concentrated $\mathrm{NaBr}$ and subjected to ultracentrifugation $(48 \mathrm{~h}$, $45000 \mathrm{rpm}$, SW 41 rotor) to obtain a total lipoprotein fraction, called the "top" fraction, and a lipoprotein-free fraction, called the "bottom" fraction. Both the top and bottom fractions were desalted by centrifugation through G-25 Sepharose spin columns before quantification of apolipoproteins.

Quantitative immunoblotting was used to determine apo A-I concentrations in dialysate fractions. Thirty to $100 \mu \mathrm{L}$ of dialysate were applied to SDS $12 \%$ polyacrylamide gels and proteins were separated by electrophoresis (16). The proteins were then electrophoretically transferred to nitrocellulose filters $(0.2 \mu \mathrm{m}$ pore size; Sartorius Filters, Inc., Hayward, CA) at $150 \mathrm{~mA}$ for 15-20 h (17). Apo A-I was detected after incubation of filters with monospecific antiserum (diluted 1:1000) followed by incubation with iodinated protein A. Antiserum for apo A-I was a generous gift from Dr. Steve Kunitake (University of California at San Francisco) and was prepared in rabbit to isolate human apo A-I. Protein bands were visualized by autoradiography and quantitated by excision and gamma-counting of the appropriate areas of the filters. Absolute concentrations of apolipoproteins were determined by comparison with standard curves of isolated apolipoproteins. Interassay variation was $12 \%$ and the sensitivity of the method was $<1 \mu \mathrm{g}$ of apo A-I/mL of dialysate concentrate. All samples were run in duplicate and intraassay variation was $2 \%$. A RIA was used to determine apo B in dialysate top and bottom fractions, using an affinity-purified rabbit antibody against human apo $\mathrm{B}$ as a probe (18).

Total protein in dialysate was determined by precipitation with $10 \%$ trichloroacetic acid (19). The average recovery with this method was $85 \pm 16 \%$.

Statistical analysis was performed using least squares linear regression, multivariate regression, the Mann-Whitney $U$ test, and the Spearman rank correlation coefficient.

\section{RESULTS}

Plasma lipoproteins. Triglyceride and cholesterol concentrations in plasma and in the VLDL, LDL, and HDL fractions, as well as plasma apolipoprotein levels of the patients, are shown in Table 1. Compared with control values (Fig. 1), TG, VLDLTG, C, VLDL-C, and LDL-C levels were increased, whereas HDL-C levels were not different. The lipid levels in the VLDL and LDL fractions were correlated with the respective total lipid levels (TG, C) in plasma. In addition, TG and VLDL-TG were positively correlated with VLDL-C $(r=0.78)$ and LDL-C $(r=$ $0.5 ; p<0.05)$, and negatively correlated with HDL-C $(r=-0.55$; $p<0.05)$ levels. Both the C/HDL-C $(5.5 \pm 2.6$ versus $3.7 \pm 1.2$; $p<0.01)$ and the LDL-C/HDL-C $(3.9 \pm 2.1$ versus $2.5 \pm 1.1 ; p$ $<0.05$ ) ratios were increased in the patients compared with control values. Compared with the control group, hypertriglyceridemia was present in $17(85 \%)$ of the patients, and six of these additionally had hypercholesterolemia; thus, $30 \%$ of the patients had combined hyperlipidemia. Compared with published normal values for children (9), 13 patients $(65 \%)$ were hypertriglyceridemic and six (30\%) had hypercholesterolemia. Figure 2 shows the distribution of lipoprotein lipid levels in our patients around the 95 th and 5th percentile (for HDL), respectively, of published normal values.

Apo A-I plasma levels in the patients were similar to those of controls $(112 \pm 26$ versus $115 \pm 26 \mathrm{mg} / \mathrm{dL})$ and were positively correlated with HDL-C levels $(r=0.83)$. Apo B plasma levels in the patients were higher than in controls $(86 \pm 27$ versus $66 \pm$ $18 \mathrm{mg} / \mathrm{dL} ; p<0.01)$ and were correlated with $\mathrm{C}(r=0.51)$ and LDL-C levels $(r=0.59)$. The apo A-I/apo B ratio was decreased in patients $(1.4 \pm 0.6$ versus $1.9 \pm 0.7 ; p<0.05)$, whereas the difference in the apo A-I/HDL-C ratio was not significant (3.2 \pm 1.2 versus $2.9 \pm 0.6$ in controls). Sex, patient age, duration of treatment with CAPD/CCPD, and diagnoses of underlying renal diseases were not correlated with other measurements.

Apolipoproteins in dialysate effluent. Apo A-I (Fig. 3) and apo B were found in the dialysate of all patients studied (Table 2). The daily loss of total protein was $2.5 \pm 1.6 \mathrm{~g}$, or $76.7 \pm 31.1$ $\mathrm{mg} / \mathrm{kg}$. The daily losses of apo A-I and apo B were not correlated with each other or their respective plasma levels. However, apo A-I losses (per $\mathrm{kg}$ ), but not apo B or total protein losses, were correlated with TG $(r=0.85)$, VLDL-TG $(r=0.76)$, and VLDL$\mathrm{C}(r=0.86)$ levels in plasma. Losses of apolipoproteins and total 
Table 1. Lipoprotein profiles in 20 children treated with CAPD/CCPD*

\begin{tabular}{|c|c|c|c|c|c|c|c|c|c|c|c|}
\hline Patient & Sex & Age (y) & TG & $\mathrm{C}$ & VLDL-TG & VLDL-C & LDL-C & HDL-C & Apo-A & Apo-B & $\%$ IBW \\
\hline J.A. & $\mathrm{M}$ & 12.1 & 127 & 145 & 41 & 21 & 79 & 45 & 143 & 84 & 129 \\
\hline E.B. & $\mathrm{M}$ & 17.7 & 149 & 189 & $\dagger$ & 48 & 120 & 21 & 85 & 68 & 95 \\
\hline M.C. & $\mathrm{F}$ & 14.6 & 208 & 260 & 96 & 20 & 202 & 38 & 109 & 127 & 100 \\
\hline A.D. & $\mathrm{M}$ & 18.0 & 85 & 172 & 20 & 8 & 129 & 35 & 102 & 105 & 136 \\
\hline T.E. & $\mathrm{F}$ & 17.8 & 119 & 211 & 44 & 9 & 126 & 76 & 167 & 82 & 92 \\
\hline J.F. & $\mathbf{M}$ & 7.4 & 190 & 197 & 78 & 26 & 143 & 28 & 90 & 94 & 112 \\
\hline V.L. & $\mathrm{F}$ & 13.1 & 254 & 212 & 132 & 30 & 160 & 22 & 73 & 67 & 103 \\
\hline M.L. & $\mathrm{F}$ & 14.3 & 178 & 119 & 87 & 28 & 74 & 17 & 69 & 54 & 93 \\
\hline V.M. & $\mathrm{F}$ & 19.0 & 131 & 197 & $\dagger$ & 14 & 134 & 49 & 120 & 113 & 85 \\
\hline S.N. & $\mathrm{M}$ & 9.8 & 177 & 190 & 76 & 19 & 140 & 31 & 92 & 89 & 102 \\
\hline R.O. & $\mathrm{M}$ & 11.7 & 132 & 181 & 14 & 8 & 123 & 50 & 136 & 118 & 106 \\
\hline I.P. & $F$ & 17.3 & 61 & 157 & 19 & 1 & 102 & 54 & 109 & 91 & 113 \\
\hline R.V. & M & 10.0 & 150 & 224 & 54 & 14 & 156 & 54 & 144 & 123 & 96 \\
\hline Mean & & 13.9 & 154 & 184 & 59 & 19 & 125 & 39 & 112 & 87 & 107 \\
\hline $\mathrm{SD}$ & & 3.4 & 62 & 36 & 34 & 11 & 33 & 16 & 26 & 27 & 16 \\
\hline
\end{tabular}

* All results are $(\mathrm{mg} / \mathrm{dL})$, unless otherwise indicated. \% IBW, percentage of ideal body wt.

$\uparrow$ Denotes missing value.

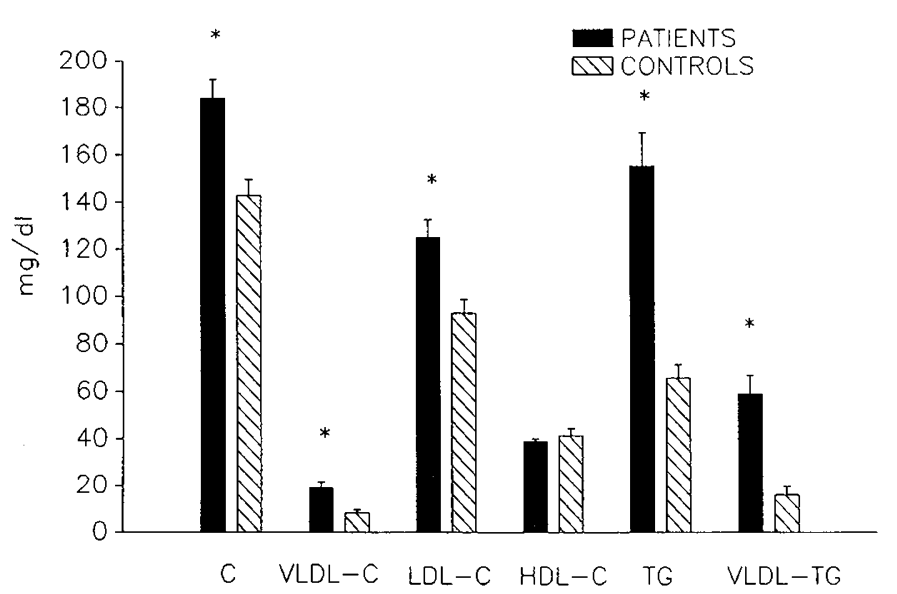

Fig. 1. Plasma lipids and lipoprotein lipids in patients $(n=20)$ and controls $(n=17)$ aged 5-19 y. The bars indicate means \pm SEM. ${ }^{*} p<$ 0.01 .

protein were not correlated with age or duration of dialysis treatment.

Nutritional status. The average nutritional status of the patients, assessed as percentage of ideal body weight, was close to $100 \%$ of ideal values $(106 \pm 16 \%)$. Similar results were found for the calculated percentages of ideal mid-arm circumference (99 $\pm 13 \%)$, mid-arm muscle circumference $(104 \pm 10 \%)$, and triceps skinfold thickness $(89 \pm 47 \%)$. None of these anthropometric measurements correlated with either the lipid levels or the apolipoprotein levels.

\section{DISCUSSION}

Our study demonstrates the presence of a highly abnormal lipoprotein profile in pediatric patients treated with CAPD/ CCPD, whether compared with a control group of similar age or with sex- and age-matched published normal values. A similar lipoprotein profile has been described in adult patients treated with CAPD (20-25), although in most studies HDL-C levels were found to be decreased, except in normotriglyceridemic patients
$(6,24)$. Our patients had normal HDL-C levels, but significant increases in total plasma lipid levels and VLDL-TG, VLDL-C, and LDL-C levels. Because cholesterol in the LDL fraction was not directly measured but calculated, it cannot be concluded from these data whether the elevated LDL-C levels in our patients were confined to LDL or whether they also included cholesterol levels in the intermediate density lipoprotein fraction. Increases in intermediate density lipoproteins, indicating defective VLDL catabolism and a high atherogenic potential, have been reported in adult patients on maintenance hemodialysis treatment (26, 27).

In our study, the C/HDL-C ratio was increased by $49 \%$ compared with controls. With an average chronologic age of 13 $y$, our patients had a C/HDLC ratio of 5.5 , clearly above the 95 th percentile of normal values for this age group (2.2) reported by the Lipid Research Clinics (28). Moreover, this ratio exceeds that of 50- to 79-y-old men (5.0) with an "average risk" for myocardial infarction who participated in the Framingham Study (29). Similarly, the LDL-C/HDL-C ratio was increased by $56 \%$, which may be of particular significance for young patients. A recent study comparing data for 105 survivors of myocardial infarction under age 45 with age-matched healthy controls found that only the LDL/HDL-C ratio and apo B levels were strongly correlated with the severity of the disease (30).

Several studies in adults have indicated that plasma apolipoprotein levels may be better predictors of atherosclerosis than lipoprotein lipid levels (31-33). In children, apo A-I and apo B and their ratio, but not serum lipids or lipoprotein lipid levels, were found to be correlated with parental myocardial infarction (34). Our patients had normal apo A-I, but elevated apo B plasma levels, resulting in a decrease of the apo A-I/apo B ratio by $26 \%$ compared with controls. Studies in adult patients treated with CAPD/CCPD have found normal $(22,35)$ or decreased (36) apo A-I and increased apo B levels $(22,36,37)$.

The presence of lipoproteins and apolipoproteins in the dialysate has been reported in previous studies $(6,38-40)$. Daily HDL-C losses ranged from 10 to $15 \mathrm{mg} \mathrm{(38)}$ in four pediatric patients, and (calculated from the data) from 26 to $65 \mathrm{mg}$ in four adult patients (6). In the latter study, it was concluded that lipoprotein losses were small and that free apolipoprotein losses were minimal. In contrast, HDL losses of approximately one 


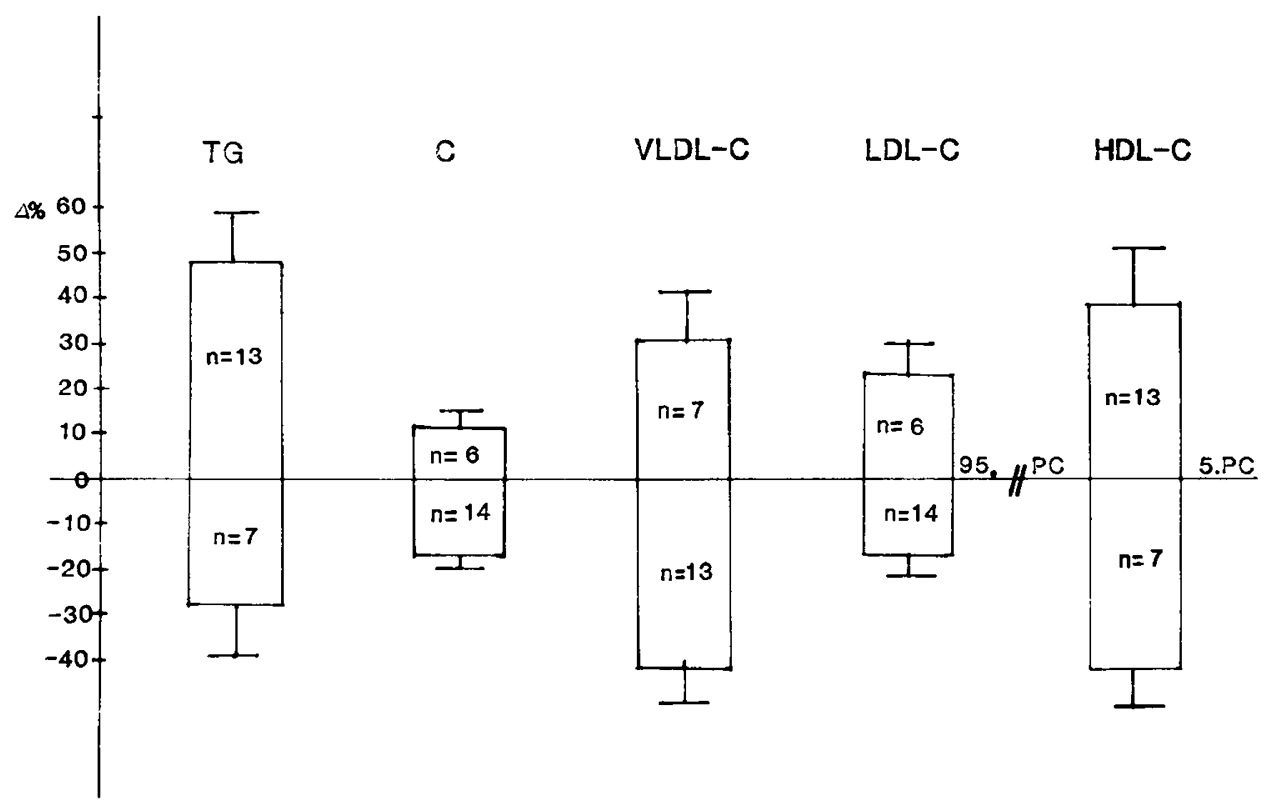

Fig. 2. Data distribution of lipoprotein lipid levels in 20 patients treated with CAPD/CCPD compared to the 95 th percentile of published values in normal children (9) of the same age and sex. The HDL-C levels were compared to the 5 th percentile. The bars indicate the means \pm SEM of $\%$ deviation from the percentile; the number of patients with levels above and below the percentile is indicated in the bars.

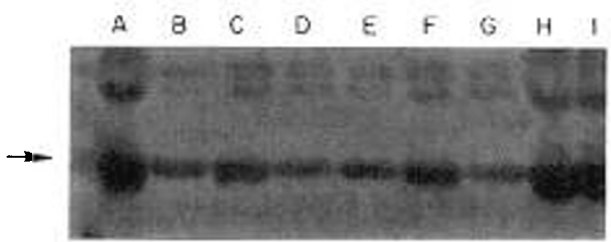

Fig. 3. Western blot showing apo A-I (bands marked by the arrow) in dialysate. Standards of known concentration were run in lanes $A, H$ and $I$. Duplicates of dialysis samples were run in lanes $B$ and $E, C$ and $F$, and $D$ and $G$.

third of the daily synthesis rate and an inverse relationship between plasma levels and the peritoneal clearance of HDL could be demonstrated in a recent study (39).

Two other studies have estimated apolipoprotein losses in the dialysate. In five adult CAPD patients, significant apo A-I losses $(52-132 \mathrm{mg} / \mathrm{d})$ and negligible apo B losses were detected with an electroimmunoassay method (37). Measured by single radial immunodiffusion, daily apo A-I and apo B losses were $83.7 \pm$ 15.1 and $38.9 \pm 12.1 \mathrm{mg}$, respectively, in another group of five adult CAPD patients (40). With a more sensitive technique, our study demonstrates considerably higher apo A-I losses, mainly due to high concentrations of free apo A-I in the dialysate. Peritoneal mass transfer of free plasma apo A-I, which normally constitutes $10 \%$ of the total plasma pool (41), but can be found in increased concentrations in patients with chronic renal failure (42), may account for the high amounts of free apo A-I in the dialysate. Another explanation might be dissociation of the apoprotein from HDL in the dialysate, inasmuch as reversible dissociation from lipoproteins is characteristic of apo A-I in plasma (43). Daily losses of apo A-I and apo B were comparable to those reported for other proteins of similar size $(44,45)$ and marked differences in dialysate losses between individuals were obvious, as noted by other investigators (44). Both proteins were present in the dialysate of all patients studied and apo A-I losses were much higher than losses of apo B. At nearly equal plasma levels of these proteins, this finding is most likely due to size-dependent peritoneal mass transfer $(44,45)$, which clearly favors apo A-I. However, preferential HDL and apo A-I losses apparently did not have a profound effect on the lipoprotein profile of these patients, inasmuch as HDL-C and apo A-I plasma levels were normal.

The average nutritional status of our patients was close to

Table 2. Apo A-I and B in dialysate*

\begin{tabular}{|c|c|c|c|c|c|c|}
\hline Patient & $\begin{array}{l}\text { A-I-top } \\
(\mathrm{mg} / \mathrm{d})\end{array}$ & $\begin{array}{l}\text { A-I-bot } \\
(\mathrm{mg} / \mathrm{d})\end{array}$ & $\begin{array}{c}\text { Total A-I } \\
(\mathrm{mg} / \mathrm{d})\end{array}$ & $\begin{array}{c}\mathrm{A}-\mathrm{I} / \mathrm{BW} \\
(\mathrm{mg} / \mathrm{kg} / \mathrm{d})\end{array}$ & $\begin{array}{l}\text { Apo B } \\
(\mathrm{mg} / \mathrm{d})\end{array}$ & $\begin{array}{c}\text { Apo B/BW } \\
(\mathrm{mg} / \mathrm{kg} / \mathrm{d})\end{array}$ \\
\hline L.R. & 16.9 & 795.4 & 812.3 & 22.0 & 20.6 & 0.6 \\
\hline J.C. & 16.5 & 852.9 & 869.4 & 26.8 & 85.6 & 2.6 \\
\hline M.V. & 22.9 & 324.2 & 347.0 & 6.9 & 23.5 & 0.5 \\
\hline I.P. & 24.8 & 333.6 & 358.4 & 7.2 & 14.1 & 0.3 \\
\hline K.B. & 32.7 & 489.3 & 522.0 & 8.7 & 17.1 & 0.3 \\
\hline N.L. & 15.1 & 453.9 & 469.0 & 9.5 & 34.8 & 0.7 \\
\hline R.V. & 3.4 & 345.3 & 348.7 & 21.1 & 173.7 & 10.5 \\
\hline Mean & 15.8 & 476.2 & 491.9 & 13.4 & 54.5 & 2.1 \\
\hline SD & 9.3 & 204.7 & 205.5 & 7.4 & 54.9 & 3.1 \\
\hline
\end{tabular}

* A-I-top, apo A-I in the top fraction (density $>1.21 \mathrm{~g} / \mathrm{mL}$ ); A-I-bot, apo A-I in the bottom fraction (density $<1.21 \mathrm{~g} / \mathrm{mL}$ ); Total A-I, total apo A-I in dialysate; A-I/BW, apo A-I losses/kg body wt/d; Apo B, total apo B in dialysate; Apo B/BW, apo B losses/kg body wt/d. 
ideal, i.e. comparable to normal children of the same height age. Plasma lipid and lipoprotein lipid levels were not correlated with indices of body fat deposition or muscle mass. Therefore, anthropometric measurements in children treated with CAPD/ CCPD do not seem to be correlated with cardiovascular risk as assessed by lipoprotein profiles.

In summary, our study demonstrates an "atherogenic" lipoprotein profile in children treated with CAPD/CCPD: high total plasma lipids (TG and C), high C/HDL-C and LDL-C/HDL-C ratios and an abnormal apolipoprotein composition with a low apo A-I/B ratio. Preliminary data from autopsies of children who underwent hemodialysis were suggestive of early atherosclerotic changes (46); however, it is yet unknown whether these lipid abnormalities will invariably lead to an accelerated course of atherosclerosis (47).

Acknowledgments. The authors thank Dr. John Elovson for advice and George Bell for technical assistance with the apo B RIA.

\section{REFERENCES}

1. Bagdade JD, Casaretto A, Albers J 1976 Effects of chronic uremia, hemodialysis, and renal transplantation on lipids and lipoproteins in man. $\mathrm{J}$ Lab Clin Med 87:37-48

2. Papadopoulou ZL, Sandler P, Tina LU, Jose PA, Calcagno PL 1981 Hyperlipidemia in children with chronic renal insufficiency. Pediatr Res 15:887-889

3. Kannel WB, Castelli W, Gordon T, McNamara PM 1971 Serum cholesterol, lipoproteins, and the risk of coronary heart disease. The Framingham study. Ann Intern Med 74:1-12

4. Salusky IB, Kopple JD, Fine RN 1983 Continuous ambulatory peritoneal dialysis in pediatric patients: a 20 -month experience. Kidney Int 24(supp 15):101-105

5. Querfeld U, Salusky IB, Nelson B, Foley J, Fine RN 1988 Hyperlipidemia in pediatric patients undergoing peritoneal dialysis. Pediatr Nephrol 2:447-452

6. Breckenridge WC, Roncari DAK, Khanna R, Oreopoulos DG 1982 The influence of continuous ambulatory peritoneal dialysis on plasma lipoproteins. Atherosclerosis 45:249-258

7. Freedman DS, Burke GL, Harsha DW, Srinivasan A, Cresanta JL, Webber LS, Berenson GS 1985 Relationship of changes in obesity to serum lipid and lipoprotein changes in childhood and adolescence. JAMA 254:515-520

8. Hubert HB, Feinleib M, McNamara PM, Castelli WP 1983 Obesity as an independent risk factor for cardiovascular disease: a 26-year follow-up of participants in the Framingham Heart Study. Circulation 67:968-977

9. Lipid Research Clinics: Population Studies Data Book 1980 Department of Health and Human Services (NIH) 80-1527, Vol 1, The Prevalence Study

10. Salusky IB, Fine RN, Nelson P, Blumenkrantz MJ, Kopple JD 1983 Nutritional status of children undergoing continuous ambulatory peritoneal dialysis. Am J Clin Nutr 38:599-611

11. National Center for Health Statistics 1977 Growth curves for children. In: Hamill PVV (ed) National Center in Health Statistics Vital Health Statistics Series 11. Data from the National Health Survey, no 165 (DHEW publication no PHS 78-1650)

12. Frisancho AR 1981 New norms of upper limb fat and muscle areas for assessment of nutritional status. Am J Clin Nutr 34:2540-2545

13. Schumaker VN, Pupione DL 1986 Sequential flotation ultracentrifugation. Methods Enzymol 128:155-170

14. Burstein M, Scholnick HR, Morfin R 1970 Rapid method for the isolation of lipoproteins from human serum by precipitation with polyanions. J Lipid Res 11:583-585

15. Mills GL, Lane PA, Weech PK 1984 A Guidebook to Lipoprotein Technique. Elsevier, New York, p 384

16. Laemmli UK 1970 Cleavage of structural proteins during the assembly of the head of bacteriophage T4. Nature 227:680-685

17. Burnette WN 1981 "Western blotting": electrophoretic transfer of proteins from sodium dodecyl sulfate-polyacrylamide gels to unmodified nitrocellulose and radiographic detection with antibody and radioiodinated protein $\mathrm{A}$ Anal Biochem 112:195-203

18. Young NL, Harvey PW, Elovson J 1987 Radioimmunoassay of rat apolipoprotein B peptides in lipoproteins and tissues. Anal Biochem 162:311-318

19. Henry RJ, Cannon DL, Winkelmann JW 1974 Clinical Chemistry: Principles and Techniques. Harper \& Row, New York, pp 423-424

20. Kawaguchi Y, Ota K, Nakagawa S, Fujinaga T, Fujimi S 1981 Continuous ambulatory peritoneal dialysis. One year's experience of cooperative study in Japan. In: Gahl GM, Kessel M, Nolph KD (eds) Advances in Peritoneal Dialysis. Excerpta Medica, Amsterdam, p 233
21. Lindholm B, Bergstroem J, Norbeck HE 1981 Lipoprotein (LP) metabolism in patients on continuous ambulatory peritoneal dialysis (CAPD). In: Gah GM, Kessel M, Nolph KD (eds) Advances in Peritoneal Dialysis. Excerpta Medica, Amsterdam, p 434

22. Keusch G, Bammatter F, Mordasini R, Binswanger U 1981 Serum lipoprotein concentrations during continuous ambulatory peritoneal dialysis. In: Gahl GM, Kessel M, Nolph KD (eds) Advances in Peritoneal Dialysis. Excerpta Medica, Amsterdam, p 427

23. Ramos JM, Heaton A, McGurk JG, Ward MK, Kerr DNS 1983 Sequential changes in serum lipids and their subfractions in patients receiving continuous ambulatory peritoneal dialysis. Nephron 35:20-23

24. Dieplinger H, Schoenfeld PY, Fielding CJ 1986 Plasma cholesterol metabolism in end-stage renal disease. J Clin Invest 77:1071-1083

25. Lindholm B, Norbeck B 1986 Serum lipids and lipoproteins during continuous ambulatory peritoneal dialysis. Acta Med Scand 220:143-151

26. Nestel JP, Fidge NH, Tan MH 1982 Increased lipoprotein-remnant formation in chronic renal failure. N Engl J Med 307:329-333

27. Ron D, Oren I, Aviram M, Better OS, Brook JG 1983 Accumulation of lipoprotein remnants in patients with chronic renal failure. Atherosclerosis 46:67-75

28. Green MS, Heiss G, Rifkind BM, Cooper GR, Williams OD, Tyroler HA 1985 The ratio of plasma high-density lipoprotein cholesterol to total and lowdensity lipoprotein cholesterol. Age-related changes and race and sex differences in selected North American populations. Circulation 72:91-104

29. Inter-Society Commission for Heart Disease Resources, Atherosclerosis Study Group 1984 Optimal resources for primary prevention of atherosclerotic diseases. Circulation 70:153A-205A

30. Hamsten A, Walldius G, Szamosi A, Dahlen G, DeFaire U 1986 Relationship of angiographically defined coronary artery disease to serum lipoproteins and apolipoproteins in young survivors of myocardial infarction. Circulation 73:1097-1110

31. Maciejko JJ, Holmes DR, Kottke BA, Zinsmeister AR, Dink DM, Mao SJT 1983. Apolipoprotein A-I as a marker of angiographically assessed coronary artery disease. N Engl J Med 309:385-389

32. Kukita H, Hamada M, Hiwada K, Kokubu T 1985 Clinical significance of measurements of serum apolipoprotein A-I, A-II and B in hypertriglyceridemic male patients with and without coronary artery disease. Atherosclerosis 55:143-149

33. Avogaro P, Cazzolato G, Bittolo Bon G, Quinci GB 1979 Are apolipoproteins better discriminators than lipids for atherosclerosis? Lancet 1:901-903

34. Freedman DS, Srinivasan SR, Shear CL, Franklin FA, Webber LS, Berenson GS 1986 The relation of apolipoproteins A-I and B in children to parental myocardial infarction. N Engl J Med 315:721-726

35. Ohta T, Hattori S, Nishiyama S, Higashi A, Matsuda I 1989 Quantitative and qualitative changes of apolipoprotein AI-containing lipoproteins in patients on continuous ambulatory peritoneal dialysis. Metabolism 38:843-849

36. Steele J, Billington T, Janus E, Moran J 1989 Lipids, lipoproteins and apolipoproteins A-I and B and aplolipoprotein losses in continuous ambulatory peritoneal dialysis. Atherosclerosis 79:47-50

37. Sniderman A, Cianflone K, Kwiterovich PO, Hutchinson T, Barre P, Prichard S 1987 Hyperapobetalipoproteinemia. The major dyslipoproteinemia in patients with chronic renal failure treated with chronic ambulatory peritoneal dialysis. Atherosclerosis 65:257-264

38. Staprans I, Piel CF, Felts JM 1986 Analysis of selected plasma constituents in continuous ambulatory peritoneal dialysis effluent. Am J Kidney Dis VII:490-494

39. Kagan A, Bar-Khayim Y, Schafer Z, Fainaru M 1990 Kinetics of peritoneal protein loss during CAPD. II. Lipoprotein leakage and its impact on plasma lipid levels. Kidney Int 37:980-990

40. Saku K, Sasaki J, Naito S, Arakawa K 1989 Lipoprotein and apolipoprotein losses during continuous ambulatory peritoneal dialysis. Nephron 51:220 224

41. Levy RI, Frederickson DS 1965 Heterogeneity of plasma high-density lipoproteins. J Clin Invest 44:426-441

42. Neary RH, Gowland E 1988 The effect of renal failure and haemodialysis on the concentration of free apolipoprotein A-1 in serum and the implication for the catabolism of high-density lipoproteins. Clin Chim Acta 171:239246

43. Eisenberg S 1948 High density lipoprotein metabolism. J Lipid Res 25:10171058

44. Young GA, Brownjohn AM, Parsons FM 1987 Protein losses in patient receiving continuous ambulatory peritoneal dialysis. Nephron 45:196-20

45. Kagan A, Bar-Khayim Y, Schafer Z, Fainaru M 1990 Kinetics of peritoneal protein losses during CAPD. I. Different characteristics for low and high molecular weight proteins. Kidney Int 37:971-979

46. Pennisi AJ, Heuser ET, Mickey MR, Lipsey A, Malekzadeh M, Fine RN 1976 Hyperlipidemia in pediatric hemodialysis and renal transplant patients. Am J Dis Child 130:957-961

47. Ritz E, Querfeld U 1989 Atherogenesis-is it accelerated in uremia? Semin Dial $2: 246-252$ 